\title{
L-Arginine Levels among Hypertensive Patients in Sokoto, North Western Nigeria
}

\author{
0. Erhabor ${ }^{1}$, A. B. Ibrahim1, Y. Abdulrahaman1, A. H. Chiroma1, M. Imoru1, F. P. Udomah', \\ M. Ahmed', K. Ibrahin', H. Buhari' ${ }^{1}$ A. Okwesili1, O. Onuigwe1, H. M. Liman' ${ }^{2}$, K. Van Dyke3, \\ N. B. Egenti' ${ }^{4}$ I. P. Iwueke ${ }^{5}$
}

\author{
${ }^{1}$ Department of Haematology and Blood Transfusion Science, Usmanu Danfodiyo University, Sokoto, Nigeria \\ ${ }^{2}$ Department of Medicine, Usmanu Danfodiyo University, Sokoto, Nigeria \\ ${ }^{3}$ Department of Biochemistry, West Virginia University, Morgantown, USA \\ ${ }^{4}$ Department of Community Medicine, University of Abuja, Abuja, Nigeria \\ ${ }^{5}$ Pathology Department, Federal Neuro Psychiatric Hospital Kware, Sokoto, Nigeria \\ Email: ${ }^{\star n} \_$osaro@yahoo.com
}

How to cite this paper: Erhabor, O., Ibrahim, A.B., Abdulrahaman, Y., Chiroma, A.H., Imoru, M., Udomah, F.P., Ahmed, M., Ibrahin, K., Buhari, H., Okwesili, A., Onuigwe, O., Liman, H.M., Van Dyke, K., Egenti, N.B. and Iwueke, I.P. (2017) LArginine Levels among Hypertensive $\mathrm{Pa}-$ tients in Sokoto, North Western Nigeria. Open Journal of Blood Diseases, 7, 1-15. https://doi.org/10.4236/ojbd.2017.71001

Received: December 16, 2016 Accepted: December 27, 2016 Published: December 30, 2016

Copyright (c) 2017 by authors and Scientific Research Publishing Inc. This work is licensed under the Creative Commons Attribution International License (CC BY 4.0).

http://creativecommons.org/licenses/by/4.0/

\begin{abstract}
Hypertension is a major public health problem that adversely affects the health status of individuals, families and communities. L-arginine levels of a total of 90 consecutively-recruited hypertensive subjects and 50 age-matched non-hypertensive controls were studied. Plasma from subjects and control participants were analyzed for L-arginine. The mean values of L-arginine level were significantly lower among the hypertensive subjects which are (174.33 \pm $78.31 \mu \mathrm{mol} / \mathrm{L})$ compared to those of the 50 non-hypertensive controls $(237.82 \pm$ $261.16 \mu \mathrm{mol} / \mathrm{L})(\mathrm{p}=0.04)$. There was no statistically significant difference in the L-arginine levels of hypertensive subjects based on gender, age and ethnicity $(\mathrm{p}=0.87,0.23$ and 0.57$)$ respectively. The L-arginine level was significantly higher among married hypertensive subjects $(181.71 \pm 78.17 \mu \mathrm{mol} / \mathrm{L}) \mathrm{com}-$ pared to single or unmarried subjects $(130.62 \pm 65.99 \mu \mathrm{mol} / \mathrm{L})(\mathrm{p}=0.03)$. The mean value of $\mathrm{L}$-arginine level was significantly higher among hypertensive subjects with mild blood pressure $(187.63 \pm 77.93 \mu \mathrm{mol} / \mathrm{L})$ compared to those with high blood pressure $(156.93 \pm 76.31 \mu \mathrm{mol} / \mathrm{L})$. The difference however was not statistically significant $(\mathrm{p}=0.05)$. The findings from this study confirm that the level of L-arginine is lower among hypertensive subjects compared to non-hypertensive controls. Age, gender and ethnicity did not have a significant effect on the L-arginine levels of hypertensive subjects. L-arginine level was significantly lower among single hypertensive patients and those with markedly raised blood pressure. It is recommended the L-arginine supplement be prescribed to hypertensive patient as a prophylactic measure. There is a need to enlighten hypertensive patients in the area on the need to maintain a balanced diet containing sufficient level of L-arginine.
\end{abstract}




\section{Keywords}

L-Arginine, Hypertensive Patients, Sokoto, Nigeria

\section{Introduction}

Hypertension (HTN or HT), also known as high blood pressure or arterial hypertension, is a chronic medical condition in which the blood pressure in the arteries is elevated. Blood pressure is expressed by two measurements, the systolic and diastolic pressures, which are the maximum and minimum pressures, respectively, in the arterial system. The systolic pressure occurs when the left ventricle is most contracted; the diastolic pressure occurs when the left ventricle is most relaxed prior to the next contraction. Normal blood pressure at rest is within the range of $100-140 \mathrm{mmHg}$ systolic and $60-90 \mathrm{mmHg}$ diastolic. Hypertension is present if the blood pressure is persistently at or above 140/90 millimeters mercury ( $\mathrm{mmHg}$ ) for most adults. In most people with established essential hypertension, increased resistance to blood flow (total peripheral resistance) accounts for the high pressure while cardiac output remains normal. Some individuals develop the typical features of established essential hypertension in later life as their cardiac output falls and peripheral resistance rises with age. The increased peripheral resistance in established hypertension is mainly attributable to structural narrowing of small arteries and arterioles although a reduction in the number or density of capillaries may also contribute. Hypertension is also associated with decreased peripheral venous compliance which may increase venous return, increase cardiac preload and, ultimately, cause diastolic dysfunction. It is defined as a transitory or sustained elevation of systemic arterial blood pressure to induce cardiovascular damage or other adverse consequences. This has become a chronic condition and a major public health problem that adversely affects health status of individuals, families and communities [1]. It is one of the most important preventable causes of premature morbidity and mortality in developed and developing countries. As of 2000, nearly one billion people or $\sim 26 \%$ of the adult population of the world had hypertension. It was common in both developed (333 million) and undeveloped (639 million) countries [2]. Hypertension is one of the most important risk factors for cardiovascular morbidity and mortality. More than a quarter of the global adult population (972 million) is currently hypertensive and almost three quarters (639 million) live in developing countries [3]. The prevalence of hypertension in $\mathrm{Ni}$ geria has increased from $11.2 \%$ in the 1990 s [4] to $27.9 \%$ in 2010 in a rural community in the Niger Delta [5] and 22.6\% in 2009 among a suburban Christian community in South-West Nigeria [6]. The prevalence of hypertension observed in Port Harcourt was 21.33\% [7]. A 2003 study carried in urban Lagos had recorded a prevalence of hypertension of $44.3 \%$, while the prevalence in rural communities in Rivers State [5] and Edo State [8] was $27.9 \%$ and $20.2 \%$ re- 
spectively.

The prevalence of hypertension has been found to be $44 \%$ in Western Europe and 28\% in North America [9]. An Indian study conducted amongst adolescent children showed that the prevalence of hypertension was about $7.0 \%$ and $2.6 \%$ amongst urban and rural children [10]. It is a major threat to the health of people in sub-Saharan Africa and a major contributor to morbidity and mortality in the sub-region [11] [12] [13] [14]. The awareness of hypertension is low in Nigeria. Previous report reported low awareness rates [15] [16] [17] [18]. Hypertension prevalence increases with age, and is a readily treatable risk factor for the most common causes of morbidity and mortality in older age: stroke, ischaemic heart disease, renal insufficiency and dementia [19] [20].

The endogenous source of NO in the body has been shown to be due to the secondary effect of L-arginine metabolism by a family of enzymes known as NO synthases (NOSs). These enzymes utilize the substrates L-arginine, molecular oxygen, and NADPH to produce L-citrulline and NO. The arginine/NOS/NO pathway appears to be very important in regulating vascular tone and remodelling in systemic hypertension. Changes in NOS expression and increased NO generation are generally interpreted to be a protective compensatory response to the underlying disease processes that increase pulmonary vascular resistance. Decreases in NO bioavailability contribute to the development of hypertension. The vasodilatory properties of NO are well characterized and are clearly important in the setting of systemic hypertension [21]. Plasma L-arginine levels have been shown to be strongly correlated with right atrial pressure, cardiac index, and $6 \mathrm{~min}$ walk distance in patients with idiopathic hypertension [22]. Inhaled NO has been shown to be a potent and selective vasodilator [23]. Although modern vasodilator therapies have displaced inhaled NO as a primary therapy for hypertension, there are some instances in which it has been demonstrated to be effective [24] such as treatment of persistent hypertension of the newborn [25] and in acute perioperative settings, such as cardiopulmonary bypass [26] [27] and post-cardiac transplant.

L-arginine is an amino acid that is necessary for the body to make protein and is found in red meat, poultry, fish, and dairy foods. L-arginine has been shown to reduce pulmonary vascular resistance in humans with hypertension [28]. The development of effective therapeutics for systemic hypertension is guided by the common pathophysiological features of vasoconstriction, thrombosis, and vascular proliferation. There is paucity of data on L-arginine levels among hypertensive patient, in Sokoto, Nigeria, West Africa and Africa. Finding from the study can potentially be used to justify the need to routinely test hypertensive patients in Sokoto in particular and Nigeria in general for plasma L-arginine. It can also help justify the need for L-arginine supplementation among hypertensive patients. It can potentially facilitate the formulation of policy on preventive programmes aimed at reducing the incidence of the disease in Nigeria. The aim of this study is to determine the levels of L-arginine among hypertensive patients in Sokoto, North Western, Nigeria. 


\section{Materials and Method}

\subsection{Study Site and Participating Hospital}

The study was conducted in the Department of Medicine Specialist Hospital Sokoto and samples were analyzed in the Department of Haematology and Blood Transfusion Science in the Faculty of Medical Laboratory Science of Usmanu Danfodio University Sokoto (UDUS). The Department and the collaborating Specialist Hospital Sokoto have enabling environment (human and material endowment) to carry out this study. Sokoto State is located in the extreme North Western part of Nigeria, near to the confluence of the Sokoto River and the Rima River. With an annual average temperature of $28.3^{\circ} \mathrm{C}\left(82.9^{\circ} \mathrm{F}\right)$, Sokoto is, on the whole, a very hot area. However, maximum daytime temperatures are for most of the year is generally under $40^{\circ} \mathrm{C}\left(104.0^{\circ} \mathrm{F}\right)$. The warmest months are February to April when daytime temperatures can exceed $45^{\circ} \mathrm{C}\left(113.0^{\circ} \mathrm{F}\right)$. The rainy season is from June to October during which showers are a daily occurrence. There are two major seasons, wet and dry which are distinct. Report from the 2007 National Population Commission indicated that the state had a population of 3.6 million [29].

\subsection{Study Population}

The study population comprised of hypertensive patients men and women attending the general outpatient clinic of Specialist Hospital Sokoto and non-hypertensive healthy men and women recruited from among student, staff of Usmanu Danfodiyo University Sokoto (UDUS) and Specialist Hospital Sokoto, Nigeria.

\subsection{Study Design}

This case-control study involved 140 consecutively-recruited participants made up of 90 hypertensive patients (subjects) presenting to the Department of Medicine of Specialist Hospital, Sokoto, Nigeria and 50 healthy, age and gender matched non-hypertensive individuals (controls) recruited from among staff of Usmanu Danfodiyo University Sokoto (UDUS) and Specialist Hospital Sokoto, Nigeria. Fifty controls were included due to cost constraints with the reagent.

\subsection{Inclusion Criteria}

The study included all consenting, consecutively recruited legal adults $(\geq 18$ years) and confirmed hypertensive patients (by a qualified physician) attending Medical Clinic in Specialist Hospital Sokoto.

\subsection{Exclusion Criteria}

The following persons who did not meet the inclusion criteria; non-adult $(<18$ years), non-hypertensive patients and non-consenting hypertensive patients were excluded from participating in this study. 


\subsection{Statistical Analysis}

The data collected was recorded on an Excel spread sheet and later subjected to statistical analysis using statistical software (SPSS Version 20.0). Results were expressed as a mean and standard deviation. Differences in values based on socio-demographic variables of subjects was determined and compared statistically. A p-value of $\leq 0.05$ was considered as significant in all statistical comparisons.

\subsection{Ethical Consideration}

Ethical clearance was obtained from the ethical committee of Specialist Hospital Sokoto. The study was carried out in accordance with the Code of Ethics for Biomedical Research involving human subjects.

\subsection{Informed Consent}

Written informed consent was obtained from all hypertensive patients and non-hypertensive individuals participating in the study. Socio-demographic information (age, gender, marital status and ethnicity) was collected using a questionnaire.

\subsection{Sample Collection and Preparation}

Three ( $3 \mathrm{ml}$ ) millilitres of whole blood will be collected from each subject into an EDTA anticoagulated tubes. The specimens were centrifuged to separate the plasma from the red cells. The plasma sample was used for plasma L-arginine estimation. L-arginine testing was carried out using the Immunodiagnostic AG (Germany) ELISA plasma L-arginine kits. This assay is based on the method of competitive enzyme linked immunoassays. The sample preparation includes the addition of a derivatization reagent for L-arginine derivatization. Afterwards, the treated samples and the polyclonal L-arginine antiserum was incubated in wells of a microtiter plate coated with an L-arginine-derivative (tracer). During the incubation period, the target $\mathrm{L}$-arginine in the sample competes with the tracer immobilized on the wall of the microtiter wells for the binding of the polyclonal antibodies. The L-arginine in the sample displaces the antibodies out of the binding to the tracer. Therefore, the concentration of the tracer bound antibody is inverse proportional to the L-arginine concentration in the sample. During the second incubation step, a peroxidase-conjugated antibody was added to each microtiter well to detect the anti-L-arginine antibodies. After washing away the unbound components tetramethylbenzidine (TMB) was added as a peroxidase substrate. Finally, the enzymatic reaction is terminated by an acidic stop solution. The color changes from blue to yellow, and the absorbance is measured in a photometer at $450 \mathrm{~nm}$. The intensity of the yellow colour is inversely proportional to the L-arginine concentration in the sample. This means that high $\mathrm{L}$-arginine concentration in the sample reduces the concentration of tracerbound antibodies and lowers the photometric signal. A dose response curve of absorbance unit (optical density, OD at $450 \mathrm{~nm}$ ) versus concentration was generated using the values obtained from the standards. L-arginine present in the 
patient samples was determined directly from this curve.

\section{Result}

Subjects for this case control study included 90 consecutively-recruited hypertensive patients aged 20 - 89 years with mean age $43.76 \pm 14.04$. Table 1 shows the L-arginine levels among hypertensive subjects and non-hypertensive controls. The mean values of $\mathrm{L}$-arginine level was significantly lower among the 90 hypertensive subjects $(174.33 \pm 78.31 \mu \mathrm{mol} / \mathrm{L})$ compared to those of the 50 non-hypertensive controls $(237.82 \pm 261.16 \mu \mathrm{mol} / \mathrm{L})(\mathrm{p}=0.04)$. Table 2 shows the effect of gender on the level of L-arginine among the hypertensive subjects. The L-arginine although marginally higher among male $(176.58 \pm 84.53 \mu \mathrm{mol} / \mathrm{L})$ compared to female hypertensive subjects $(173.31 \pm 84.53 \mu \mathrm{mol} / \mathrm{L})$. The difference however was not statistically significant $(p=0.87)$. Table 3 shows the effect age on the level of $\mathrm{L}$-arginine among hypertensive subjects. The mean $\mathrm{L}$-arginine level was compared based on age of the hypertensive subjects. The mean L-arginine level was marginally higher among hypertensive subjects in the 40 89 years age group $(184.71 \pm 76.32 \mu \mathrm{mol} / \mathrm{L})$ compared to the 20 - 39 years age group $(164.83 \pm 79.70 \mu \mathrm{mol} / \mathrm{L})$. The difference was however not statistically significant $(\mathrm{p}=0.23)$. Table 4 shows the effect of marital status on $\mathrm{L}$-arginine among hypertensive patients. The effect of marital status on L-arginine levels of

Table 1. Mean L-arginine levels among hypertensive subjects and non-hypertensive controls.

\begin{tabular}{ccccc}
\hline \multirow{2}{*}{ Parameter } & \multicolumn{3}{c}{ Hypertensive Subjects and Non-Hypertensive Controls } & \multicolumn{2}{c}{ t-value p-value } \\
\cline { 2 - 5 } & Subjects Mean \pm SD N = 90 & Controls Mean \pm SD N = 50 & & \\
\hline L-arginine $(\mu \mathrm{mol} / \mathrm{L})$ & $174.33 \pm 78.31$ & $237.82 \pm 261.16$ & -2.11 & 0.04 \\
\hline
\end{tabular}

Table 2. Effect of gender on the level of L-arginine levels among hypertensive subjects.

\begin{tabular}{ccccc}
\hline \multirow{2}{*}{ Parameter } & \multicolumn{3}{c}{ Gender } & \\
\cline { 2 - 5 } & Male Mean \pm SD N = 62 & Female Mean \pm SD N = 28 & & t-value p-value \\
\hline L-arginine $(\mu \mathrm{mol} / \mathrm{L})$ & $176.58 \pm 84.53$ & $173.31 \pm 84.53$ & -160 & 0.87 \\
\hline
\end{tabular}

Table 3. Effect of age on mean L-arginine levels among hypertensive subjects.

\begin{tabular}{|c|c|c|c|}
\hline \multirow{2}{*}{ Parameter } & \multicolumn{2}{|c|}{ Age } & \multirow{2}{*}{ t-valuep-value } \\
\hline & $20-39$ Years Mean \pm SD $N=47$ & $40-89$ Years Mean \pm SD $N=43$ & \\
\hline $\begin{array}{c}\text { L-arginine } \\
(\mu \mathrm{mol} / \mathrm{L})\end{array}$ & $164.83 \pm 79.70$ & $184.71 \pm 76.32$ & -1.23 \\
\hline
\end{tabular}

Table 4. Effect of marital status on L-arginine levels among hypertensive patients.

\begin{tabular}{ccccc}
\hline \multirow{2}{*}{ Parameter } & \multicolumn{3}{c}{ Marital Status } & \\
\cline { 2 - 4 } & Married Mean \pm SD N =77 & Single Mean \pm SD N = 13 & & \\
\hline L-arginine $(\mu \mathrm{mol} / \mathrm{L})$ & $181.71 \pm 78.17$ & $130.62 \pm 65.99$ & 2.23 & 0.03 \\
\hline
\end{tabular}


hypertensive subjects was investigated. The L-arginine level was significantly higher among married hypertensive subjects $(181.71 \pm 78.17 \mu \mathrm{mol} / \mathrm{L})$ compared to single or unmarried subjects $(130.62 \pm 65.99 \mu \mathrm{mol} / \mathrm{L})(\mathrm{p}=0.03)$. Table 5 shows the effect of ethnicity on the L-arginine among hypertensive patients. The L-arginine level was marginally higher among hypertensive subjects of the Hausa ethnic group $(177.12 \pm 79.73 \mu \mathrm{mol} / \mathrm{L})$ compared to the Fulani ethnic group $(166.21 \pm 75.11 \mu \mathrm{mol} / \mathrm{L})$. The difference however was not statistically significant $(\mathrm{p}=0.57)$. Table 6 shows the relationship the effect of blood pressure on L-arginine and nitric oxide level among hypertensive patient. L-arginine levels among hypertensive were compared based on their blood pressure levels. The mean value of L-arginine level was significantly $(\mathrm{p}=0.05)$ higher among hypertensive subjects with mild blood pressure $(187.63 \pm 77.93 \mu \mathrm{mol} / \mathrm{L})$ compared to those with high blood pressure $(156.93 \pm 76.31 \mu \mathrm{mol} / \mathrm{L})$.

\section{Discussion}

Hypertension has become a chronic condition and a major public health problem that adversely affects health status of individuals, families and communities. Worldwide hypertension is estimated to cause 7.1 million premature deaths and $4.5 \%$ of the disease burden. The population of global disease burden attributable to hypertension is substantial.

This study investigated the level of L-arginine among hypertensive subjects and non-hypertensive controls. The result obtained from this study showed that the mean L-arginine level was significantly lower $(p=0.04)$ among the hypertensive subjects compared to the non-hypertensive controls. Our finding is consistent with a previous report which indicated that $\mathrm{L}$-arginine levels are reduced in Pre-eclampsia (PE), a syndrome of pregnancy-induced hypertension [30]. Arginine deficiency or lack of availability, and changes in arginine metabolism, has the potential to contribute to increased blood pressure and endothelial cell dysfunction [31].

This study also considered effect of gender on the L-arginine level among hypertensive subjects. The L-arginine level was marginally higher among males compared to female hypertensive subjects $(\mathrm{p}=0.87)$. The reason for lower level of L-arginine observed among female hypertensive subjects is not known. It is not known whether menstrual cycle, pregnancy, hormones and lactation may

Table 5. Effect of ethnicity on L-arginine levels among hypertensive patients.

\begin{tabular}{ccccc}
\hline \multirow{2}{*}{ Parameter } & \multicolumn{3}{c}{ Ethnic Group } & t-value p-value \\
\cline { 2 - 5 } & Hausa Mean \pm SD N =67 & Fulani Mean \pm SD N = 23 & & \\
\hline L-arginine $(\mu \mathrm{mol} / \mathrm{L})$ & $177.12 \pm 79.73$ & $166.21 \pm 75.11$ & 0.57 & 0.57 \\
\hline
\end{tabular}

Table 6. Effect of blood pressure on the L-arginine level among hypertensive patient.

\begin{tabular}{ccccc}
\hline \multirow{2}{*}{ Parameter } & \multicolumn{2}{c}{ Blood Pressure Level } & \multicolumn{2}{c}{ t-value p-value } \\
\cline { 2 - 5 } & High BP Mean \pm SD N = 39 & Mild BP Mean \pm SD N = 51 & & \\
\hline L-arginine $(\mu \mathrm{mol} / \mathrm{L})$ & $156.93 \pm 76.31$ & $187.63 \pm 77.93$ & -1.93 & 0.05 \\
\hline
\end{tabular}


play a role. However, the incidence of uncontrolled hypertension has been shown to be greater in men than in women [32]. Although the mechanisms responsible for the gender differences in $\mathrm{L}$-arginine and blood pressure control are not clear, there is significant evidence that androgens, such as testosterone, play an important role in gender-associated differences in blood pressure regulation [33] [34].

Our study also investigated the effect of age on the L-arginine level among hypertensive patient subjects. The L-arginine was marginally higher among older subjects (40 - 82 years) compared to younger hypertensive subjects (20 - 39 years) $(\mathrm{p}=0.23)$. The reason for this age-related difference in the L-arginine and nitric oxide among hypertensive subjects is unknown. Socioeconomic status, psychosocial stressors/risks, and other environmental factors may play a role. Previous report shows that aging in rats is associated with a reduction in NO substrate (L-arginine) and excretion of NO metabolites [34]. In addition, the Third National Health and Nutrition Evaluation Survey (NHANES III) showed that, in general, men had higher blood pressure than women through middle age [35].

The effect of marital status on the L-arginine of hypertensive was investigated. The L-arginine level was significantly higher $(\mathrm{p}=0.03)$ among married hypertensive subjects compared to those who were single. The reason for this marital status-related difference is not known. Less psychosocial distress and better access to dietary sources of L-arginine including meat, fish, soy, beans, lentils, whole grains and nuts among married hypertensive subjects may be responsible [36]. Also, married individuals are more likely to make better informed decisions compared to singles. Singles are also more likely to be involved in high risk behaviors that expose them to more psychological distress and decreased L-arginine.

The L-arginine level of hypertensive subjects were compared based on ethnicity. The L-arginine was marginally higher among the Hausa ethnic group compared to the Fulani ethnic group ( $p=0.57)$. Our finding of an ethnic variation in the level of L-arginine among hypertensive subjects of African descent in Sokoto is consistent with previous report which indicated that the $\mathrm{L}$-arginine is affected by psychosocial distress with higher susceptibility in Black Africans. This interaction may contribute to the higher cardiovascular disease risk in Black Africans [37]. It is becoming particularly clear that there is a 2- to 3 -fold racial difference in certain cardiovascular diseases (pre-eclampsia) associated with dysfunctional nitric oxide-mediated vasodilation [38]. The phenomenon of ethnic health disparities in cardiovascular and many other diseases is becoming clear, and awareness of the importance in addressing these differences in the diagnosis and treatment of various diseases is growing. Ethnic diversity is a factor in a variety of pathophysiological processes, including responses to stress, psychological issues, and communication between health care professionals and patients. In particular, African Americans and Africans (AA) are disproportionately affected by hypertension, which causes an estimated $30 \%$ and $20 \%$ of all deaths in AA 
men and women, respectively [39] [40]. African Americans have a more virulent course of hypertension, with higher rates of target organ damage, including heart failure, end-stage renal disease, myocardial infarct, and stroke as compared with non-African Americans [41] [42] [43]. The mechanisms underlying these racial disparities in the level of L-arginine between hypertensive subjects of Hausa and Fulani ethnic groups are multifactorial and may include genetic factors, socioeconomic status, psychosocial stressors/risks, and other environmental factors. It has been proposed that the observed racial differences in the prevalence in cardiovascular diseases, diabetes associated with renal failure, and even pre-eclampsia occurring in pregnancy could be, at least in part, attributed to decreased NO-mediated vasodilation in various vascular beds [44]. NO-dependent vasodilation can be affected at the levels of either diminished NO production or increased NO degradation, thus rendering less NO bioavailable to target cells. Similarly, previous report indicated that by 60 to 69 years of age, non-Hispanic Black and Hispanic women developed higher blood pressure than men of similar ethnic background [45].

Hypertension, also known as high blood pressure or arterial hypertension, is a chronic medical condition in which the blood pressure in the arteries is elevated. Blood pressure is expressed by two measurements, the systolic and diastolic pressures, which are the maximum and minimum pressures, respectively, in the arterial system. The systolic pressure occurs when the left ventricle is most contracted; the diastolic pressure occurs when the left ventricle is most relaxed prior to the next contraction. Normal blood pressure at rest is within the range of 100 $140 \mathrm{mmHg}$ systolic and $60-90 \mathrm{mmHg}$ diastolic. Hypertension is present if the blood pressure is persistently at or above 140/90 millimeters mercury ( $\mathrm{mmHg}$ ) for most adults; different criteria apply to children [46]. Blood pressure falls during sleep and rises rapidly just before we wake up, which is when the risk of cardiovascular events is the highest. Therefore, a definition of hypertension is usually taken as that level of arterial blood pressure associated with doubling of long-term cardiovascular risk [47]. The relationship between blood pressure and L-arginine was investigated among hypertensive subjects. The L-arginine level was lower $(\mathrm{p}=0.05)$ among hypertensive patients with markedly raised blood pressure compared to those with mildly raised normal blood pressure. Arginine is a key player in a set of physiological functions that interact to maintain vascular health and homeostasis. Arginine is used in the formation of creatine which is subsequently converted to creatine phosphate, a major source of ATP, the energy source for muscle contraction and other energy demanding processes such as cellular membrane pumps. Because the substrate for NOS in the formation of the potent vasodilator NO, arginine is essential in the NO pathway. Another means by which arginine influences vasodilation is via insulin [48]. Arginine promotes insulin release from the beta cells of the pancreas [49] and in turn, insulin decreases plasma asymmetric dimethylarginine (ADMA) concentrations [50] and stimulates cellular uptake of arginine. Binding of insulin to insulin receptors stimulates the production of NO via activation of an insulin- 
signaling pathway [51] resulting in an insulin-mediated vasodilation [52]. Arginine has been shown to have antioxidant activities [53], which may help to regulate redox-sensitive proteins and may lower blood pressure.

Arginine is involved in several important physiological processes, many of which impact vascular function. Arginine deficiency or lack of availability, and changes in arginine metabolism, has the potential to contribute to increased blood pressure and endothelial cell dysfunction. The question often arises-is arginine supplementation effective in preventing or treating hypertension, and if so, what is the mechanism? Potential role of L-arginine supplementation as a new effective strategy of improving endothelial function in patients with hypertension is recently under consideration. Previous report indicates that L-arginine supplementation increases plasma arginine, citrulline and TAS in patients with mild arterial hypertension. Augmented concentrations of L-arginine stimulate NO biosynthesis which leads to reduction of oxidative stress [54]. Similarly, Chen and colleagues [55] have shown that oral arginine $(1.25 \mathrm{~g} / \mathrm{L}$ in drinking water for four weeks) prevented hypertension and nephrosclerosis in these animals. Observation from an animal study also indicated that supplemental l-arginine exhibited a significant pulmonary vasodilatory effect, as shown by a decreased pulmonary arterial pressure (PAP), decreased right ventricular hypertrophy and improved endothelium-dependent relaxation in rats. Also, oral 1 -arginine administration was shown in a previous study to produce an increased plasma l-arginine levels about two-fold [53]. Although the etiology of hypertension has a genetic component, lifestyle factors such as diet play an important role. A diet rich in protein containing the semi-essential amino acid, arginine, and arginine treatment, lowers blood pressure in humans and in animal models [31]. The Dietary Approaches to Stop Hypertension (DASH) study demonstrated that the DASH diet, rich in vegetables, fruits and low-fat dairy products; low in fat; and including whole grains, poultry, fish and nuts, lowered blood pressures. A diet rich in protein containing the semi essential amino acid, arginine, and arginine treatment lowers blood pressure in humans and in animal models [31].

\section{Conclusion}

In conclusion, the findings in this study confirmed that the level of L-arginine and Nitric Oxide is lower among hypertensive patient compared to non-hypertensive controls. The level L-arginine was lower among unmarried hypertensive patients compared to married hypertensive patients and among hypertensive patients with markedly raised blood pressure compared to those with mildly raised blood pressure level.

\section{Recommendations}

We recommend that a further research study should be conducted involving a larger population of hypertensive patient to determine the level of and L-arginine. We also recommend that L-arginine supplements be prescribed routinely 
to hypertensive patient as a prophylaxic measure. There is need for public enlightenment programme to educate hypertensive patients on the need to maintain a balanced diet containing sufficient amount of L-arginine containing food. It is recommended that facilities for the routine monitoring of L-arginine among hypertensive in the area be provided.

\section{References}

[1] Chobanian, A.V., Bakris, G.L., Black, H.R., Cushman, W.C. and Green, L.A. (2003) Seventh Report of the Joint National Committee on Prevention, Detection, Evaluation, and Treatment of High Blood Pressure. Hypertension, 42, 1206-1252. https://doi.org/10.1161/01.HYP.0000107251.49515.c2

[2] Kearney, P.M., Whelton, M., Reynolds, K., et al. (2005) Global Burden of Hypertension: Analysis of Worldwide Data. Lancet, 365, 217-223. https://doi.org/10.1016/S0140-6736(05)70151-3

[3] Mohan, S., Campbell, N. and Chockalingam, A. (2005) Management of Hypertension in Low and Middle Income Countries: Challenges and Opportunities. Prevention and Control, 1, 275-284. https://doi.org/10.1016/j.precon.2006.04.001

[4] National Expert Committee Report on Non-Communicable Diseases in Nigeria (1997).

[5] Wokoma, F.S. and Alasia, D.D. (2011) Blood Pressure Pattern in Barako: A Rural Community in Rivers State, Nigeria. Nigerian Health Journal, 11, 8-13.

[6] Adefuye, B.O., Adefuye, P.O., Oladapo, O.T., Familoni, O.B. and Olurunga, T.O. (2009) Prevalence of Hypertension and Other Cardiovascular Risk Factors in an African Sub-Urban Religious Community. Nigerian Medical Practice, 55, 4-8.

[7] Ordinioha, B. (2013) The Prevalence of Hypertension and Its Modifiable Risk Factors among Lecturers of a Medical School in Port Harcourt, South-South Nigeria: Implications for Control Effort. Nigerian Journal of Clinical Practice, 16, 1-4. https://doi.org/10.4103/1119-3077.106704

[8] Omuemu, V.O., Okojie, O.H. and Omuemu, C.E. (2007) Awareness of High Blood Pressure Status, Treatment and Control in a Rural Community in Edo State. Nigerian Journal of Clinical Practice, 10, 208-212.

[9] Cooper, R.S., Liao, Y. and Rotimi, C. (1996) Is Hypertension More Severe among U.S. Blacks, or Is Severe Hypertension More Common? Annals of Epidemiology, 6, 173-180. https://doi.org/10.1016/1047-2797(96)00009-9

[10] Mohan, B., Kumar, N., Aslam, N., Rangbulla, A. and Kumbkarni, S. (2004) Prevalence of Hypertension and Obesity in Urban and Rural Going School in India. Indian Heart Journal, 56, 310-314.

[11] Okojie, O.H. and Omuemu, C.E. (2007) Awareness of High Blood Pressure Status, Treatment and Control in a Rural Community in Edo State. Nigerian Journal of Clinical Practice, 10, 208-212.

[12] Ekore, R.I., Ajayi, I.O. and Arije, A. (2009) Case Finding for Hypertension in Young Adult Patients Attending a Missionary Hospital in Nigeria. African Health Sciences, 9, 193-199.

[13] Isezuo, S.A., Sabir, A.A., Ohwovorilole, A.E. and Fasanmade, O.A. (2011) Prevalence, Associated Factors and Relationship between Prehypertension and Hypertension: A Study of Two Ethnic African Populations in Northern Nigeria. Journal of Human Hypertension, 25, 224-230. https://doi.org/10.1038/jhh.2010.56

[14] Onwuchekwa, A.C., Mezie-Okoye, M.M. and Babatunde, S. (2012) Prevalence of 
Hypertension in Kegbara-Dere, a Rural Community in the Niger Delta Region, Nigeria. Ethnic Diseases, 22, 340-346.

[15] Ekwunife, O.I., Udeogaranya, P.O. and Nwatu, I.L. (2010) Prevalence, Awareness, Treatment and Control of Hypertension in a Nigerian Population. Health, 7, 731735. https://doi.org/10.4236/health.2010.27111

[16] Oladapo, O.O., Salako, L., Sodiq, O., Soyinka, K. and Adedapo, K. (2010) A Prevalence of Cardiometabolic Risk Factors among a Rural Yoruba South-Western Nigerian Population: A Population-Based Survey. Cardiovascular Journal Africa, 21, 26-31.

[17] Ejim, E.C., Okafor, C.I., Emehel, A., Mbah, A.U. and Onyia, U. (2011) Prevalence of Cardiovascular Risk Factors in the Middle-Aged and Elderly Population of a Nigerian Rural Community. Journal of Tropical Medicine, 2011, Article ID: 308687. https://doi.org/10.1155/2011/308687

[18] Ulasi, I.I., Ijoma, C.K., Onwubere, B.J., Arodiwe, E. and Onodugo, O. (2011) High Prevalence and Low Awareness of Hypertension in a Market Population in Enugu, Nigeria. International Journal of Hypertension, 2011, Article ID: 869675.

https://doi.org/10.4061/2011/869675

[19] Ferri, C.P., Schoenborn, C., Kalra, L., Acosta, D., Guerra, M. (2011) Prevalence of Stroke and Related Burden among Older People Living in Latin America, India and China. Journal of Neurology and Neurosurgery Psychiatry, 26, 511-519. https://doi.org/10.1136/jnnp.2010.234153

[20] Ikeda, N., Saito, E., Kondo, N., Inoue, M. and Ikeda, S. (2011) What Has Made the Population of Japan Healthy? Lancet, 378, 1094-1095.

https://doi.org/10.1016/S0140-6736(11)61055-6

[21] Zuckerbraun, B.S., Stoyanovsky, D.A., Sengupta, R., Shapiro, R.A. and Ozanich, B.A. (2007) Nitric Oxide-Induced Inhibition of Smooth Muscle Cell Proliferation Involves S-Nitrosation and Inactivation of RhoA. American Journal of Physiology and Cell Physiology, 292, C824-C831. https://doi.org/10.1152/ajpcell.00592.2005

[22] Beyer, J., Kolditz, M., Ewert, R., Rubens, C., Opitz, C. and Schellong, S. (2008) $L$-Arginine Plasma 5 Inhibition in Patients with Sickle Cell Disease Who Are on Hydroxyurea Therapy. European Journal of Haematology, 82, 315-332.

[23] Pepke-Zaba, J., Higenbottam, T.W., Dinh-Xuan, A.T., Stone, D. and Wallwork, J. (1991) Inhaled Nitric Oxide as a Cause of Selective Pulmonary Vasodilatation in Pulmonary Hypertension. Lancet, 338, 1173-1174. https://doi.org/10.1016/0140-6736(91)92033-X

[24] Michelakis, E.D., McMurtry, M.S., Wu, X.C., Dyck, J.R. and Moudgil, R. (2002) Dichloroacetate, a Metabolic Modulator, Prevents and Reverses Chronic Hypoxic Pulmonary Hypertension in Rats: Role of Increased Expression and Activity of Voltage-Gated Potassium Channels. Circulation, 105, 244-250. https://doi.org/10.1161/hc0202.101974

[25] Roberts, J.D., Fineman, J.R., Morin, F.C., Shaul, P.W. and Rimar, S. (1997) Inhaled Nitric Oxide and Persistent Pulmonary Hypertension of the Newborn. The Inhaled Nitric Oxide Study Group. New England Journal of Medicine, 336, 605-610. https://doi.org/10.1056/NEJM199702273360902

[26] Wessel, D.L., Adatia, I., Giglia, T.M., Thompson, J.E. and Kulik, T.J. (1993) Use of Inhaled Nitric Oxide and Acetylcholine in the Evaluation of Pulmonary Hypertension and Endothelial Function after Cardiopulmonary Bypass. Circulation, 88, 2128-2138. https://doi.org/10.1161/01.CIR.88.5.2128

[27] Ardehali, A., Hughes, K., Sadeghi, A., Esmailian, F., Marelli, D. and Moriguchi, J. (2001) Inhaled Nitric Oxide for Pulmonary Hypertension after Heart Transplanta- 
tion. Transplantation, 72, 638-641.

https://doi.org/10.1097/00007890-200108270-00013

[28] Nagaya, N., Uematsu, M., Oya, H., Sato, N., Sakamaki, F. and Kyotani, S. (2001) Short-Term Oral Administration of L-Arginine Improves Hemodynamics and Exercise Capacity in Patients with Precapillary Pulmonary Hypertension. American Journal of Respiratory and Critical Care Medicine, 163, 887-891. https://doi.org/10.1164/ajrccm.163.4.2007116

[29] National Population Commission (NPC) (2007) National Census Figures. Abuja.

[30] Adriana, M.L., Pimentel, N.R., Pereira, C.A., Costa, G.E., Mann, V.S.C., Cordeiro, R.S., de Moura, T.M.C., Brunini, A.C.M. and Ângela C.R. (2013) L-Arginine-Nitric Oxide Pathway and Oxidative Stress in Plasma and Platelets of Patients with Pre-Eclampsia. Hypertension, Research, 36, 783-788.

https://doi.org/10.1038/hr.2013.34

[31] Vasdev, S. and Gill, V. (2008) The Antihypertensive Effect of Arginine. International Journal of Angiology, 17, 7-22. https://doi.org/10.1055/s-0031-1278274

[32] Anastos, K., Charney, P., Cohen, E., Jones, C.Y., Marte, C., Swiderski, D.M., Wheat, M.E. and Williams, S. (1991) Hypertension in Women: What Is Really Known? The Women's Caucus, Working Group on Women's Health of the Society of General Internal Medicine. Annals of Internal Medicine, 115, 287-293. https://doi.org/10.7326/0003-4819-115-4-287

[33] Harshfield, G.A., Alpert, B.S., Pulliam, D.A., Somes, G.W. and Wilson, D.K. (1994) Ambulatory Blood Pressure Recordings in Children and Adolescents. Pediatrics, 94, 180-184.

[34] Reckelhoff, J.F., Zhang, H., Srivastava, K. and Granger, J.P. (1999) Gender Differences in Hypertension in Spontaneously Hypertensive Rats: Role of Androgens and Androgen Receptor. Hypertension, 34, 920-923. https://doi.org/10.1161/01.HYP.34.4.920

[35] Burl, V.L., Whelton, P., Roccella, E.J., Brown, C., Cutler, J.A., Higgins, M., Horan, M.J. and Labarthe, D. (1995) Prevalence of Hypertension in the US Adult Population: Results from the Third National Health and Nutrition Examination Survey, 1988-1991. Hypertension, 25, 305-313. https://doi.org/10.1161/01.HYP.25.3.305

[36] Higashi, Y., Oshima, T., Watanabe, M., Matsuura, H. and Kajiyama, G. (1996) Renal Response to $L$-Arginine in Salt-Sensitive Patients with Essential Hypertension. Hypertension, 27, 643-648. https://doi.org/10.1161/01.HYP.27.3.643

[37] Glyn, M.C., Anderssohn, M., Lüneburg, N., Van Rooyen, J.M., et al. (2012) Ethnicity-Specific Differences in L-Arginine Status in South African Men. Journal of Human Hypertension, 26, 737-743. https://doi.org/10.1038/jhh.2011.103

[38] Mata-Greenwood, E. and Chen, D. (2008) Racial Differences in Nitric Oxide-Dependent Vasorelaxation. Reproductive Science, 15, 9-25. https://doi.org/10.1177/1933719107312160

[39] Hajjar, I. and Kotchen, T.A. (2003) Trends in Prevalence, Awareness, Treatment, and Control of Hypertension in the United States, 1988-2000. Journal of American Medical Association, 290, 199-206. https://doi.org/10.1001/jama.290.2.199

[40] Lapu-Bula, R. and Ofili, E. (2007) From Hypertension to Heart Failure: Role of Nitric Oxide-Mediated Endothelial Dysfunction and Emerging Insights from Myocardial Contrast Echocardiography. American Journal of Cardiology, 99, 7D-14D. https://doi.org/10.1016/j.amjcard.2006.12.014

[41] Schocken, D.D., Arrieta, M.I., Leaverton, P.E. and Ross, E.A. (1992) Prevalence and Mortality Rate of Congestive Heart Failure in the United States. Journal of American College of Cardiology, 20, 301-306. 
https://doi.org/10.1016/0735-1097(92)90094-4

[42] Alderman, M.H., Cohen, H.W. and Madhavan, S. (2000) Myocardial Infarction in Treated Hypertensive Patients: The Paradox of Lower Incidence but Higher Mortality in Young Blacks Compared with Whites. Circulation, 101, 1109-1114. https://doi.org/10.1161/01.CIR.101.10.1109

[43] Kissela, B., Schneider, A. and Kleindorfer, D. (2004) Stroke in a Biracial Population: The Excess Burden of Stroke among Blacks. Stroke, 35, 426-431. https://doi.org/10.1161/01.STR.0000110982.74967.39

[44] Benjamin, I.J., Arnett, D.K. and Loscalzo, J. (2005) Discovering the Full Spectrum of Cardiovascular Disease: Minority Health Summit 2003: Report of the Basic Science Writing Group. Circulation, 111, e120-e123. https://doi.org/10.1161/01.cir.0000157741.99920.0c

[45] Burl, V.L., Whelton, P., Roccella, E.J., Brown, C., et al. (1995) Prevalence of Hypertension in the US Adult Population: Results from the Third National Health and Nutrition Examination Survey, 1988-1991. Hypertension, 25, 305-313. https://doi.org/10.1161/01.HYP.25.3.305

[46] James, P.A., Oparil, S., Carter, B.L., Cushman, W.C. and Dennison-Himmelfarb, C. (2013) Evidence-Based Guideline for the Management of High Blood Pressure in Adults: Report from the Panel Members Appointed to the Eighth Joint National Committee (JNC 8). Journal of American Medical Association, 311, 507-520. https://doi.org/10.1001/jama.2013.284427

[47] Kaplan, N.M. (2002) Kaplan's Clinical Hypertension. 8th Edition, Lippincott Williams \& Wilkins, Philadelphia.

Rastogi, D., Ngai, P., Barst, R.J. and Koumbourlis, A.C. (2004) Lower Airway Obstruction, Bronchial Hyperresponsiveness, and Primary Pulmonary Hypertension in Children. Paediatric Pulmonology, 37, 50-55. https://doi.org/10.1002/ppul.10363

[48] Sener, A., Best, L.C. and Yates, A.P. (2000) Stimulus-Secretion Coupling of Arginine-Induced Insulin Release: Comparison between the Cationic Amino Acid and Its Methyl Ester. Endocrine, 13, 329-340. https://doi.org/10.1385/ENDO:13:3:329

[49] Higashi, Y., Oshima, T. and Ono, N. (1995) Intravenous Administration of L-Arginine Inhibits Angiotensin-Converting Enzyme in Humans. Journal of Clinical Endocrinology and Metabolism, 80, 2198-2202.

[50] Zeng, G., Nystrom, F.H. and Ravichandran, L.V. (2000) Roles for Insulin Receptor, PI3-Kinase, and Act in Insulin-Signaling Pathways Related to Production of Nitric Oxide in Human Vascular Endothelial Cells. Circulation, 101, 1539-1545. https://doi.org/10.1161/01.CIR.101.13.1539

[51] Scherrer, U., Randin, D., Vollenweider, P., Vollenweider, L. and Nicod, P. (1994) Nitric Oxide Release Accounts for Insulin's Vascular Effects in Humans. Journal of Clinical Investigation, 94, 2511-2515. https://doi.org/10.1172/JCI117621

[52] Lubec, B., Hayn, M., Kitzmuller, E., Vierhapper, H. and Lubec, G. (1997) $L$-Arginine Reduces Lipid Peroxidation in Patients with Diabetes Mellitus. Free Radicals Biology Medicine, 22, 355-357. https://doi.org/10.1016/S0891-5849(96)00386-3

[53] Jabecka, A., Ast, J., Bogdaski, P., Drozdowski, M., Pawlak-Lemaska, K., Cielewicz, A.R. and Pupek-Musialik, D. (2012) Oral L-Arginine Supplementation in Patients with Mild Arterial Hypertension and Its Effect on Plasma Level of Asymmetric Dimethylarginine, L-Citruline, L-Arginine and Antioxidant Status. European Review in Medical Pharmacological Sciences, 16, 1665-1674.

[54] Chen, P.Y., St John, P.L., Kirk, K.A., Abrahamson, D.R. and Sanders, P.W. (1993) 
Hypertensive Nephrosclerosis in the Dahl/Rapp Rat. Initial Sites of Injury and Effect of Dietary L-Arginine Supplementation. Laboratory Investigation, 68, 174-184.

[55] Shigeru, S., Miki, A., Tomohiko, U., Norikazu, N., Kazuo, M., Tadao, M. and Akira M. (2004) Nitric Oxide Formation and Plasma L-Arginine Levels in Pulmonary Hypertensive Rats. Respiratory Medicine, 98, 205-212.

https://doi.org/10.1016/j.rmed.2003.09.013

Submit or recommend next manuscript to SCIRP and we will provide best service for you:

Accepting pre-submission inquiries through Email, Facebook, LinkedIn, Twitter, etc. A wide selection of journals (inclusive of 9 subjects, more than 200 journals)

Providing 24-hour high-quality service

User-friendly online submission system

Fair and swift peer-review system

Efficient typesetting and proofreading procedure

Display of the result of downloads and visits, as well as the number of cited articles Maximum dissemination of your research work

Submit your manuscript at: http://papersubmission.scirp.org/

Or contact ojbd@scirp.org 